\title{
Towards a Detailed Understanding of Preschool Children's Memory-Related Functioning and Emotion Regulation: The Role of Parents' Observed Reminiscence Style, Memory Valence, and Parental Gender
}

\author{
Jolene van der Kaap-Deeder \\ Norwegian University of Science and Technology
}

\author{
Athanasios Mouratidis \\ Bilkent University
}

Peter Krøjgaard
Aarhus University

\author{
Bart Soenens \\ Ghent University
}

Sarah De Pauw

Ghent University

Maarten Vansteenkiste

Ghent University

\begin{abstract}
This study examined the role of parents' reminiscing style in preschoolers' memory-related functioning and general emotion regulation. In 87 families, each parent rated their child's $\left(M_{\text {age }}=4.07\right.$ years, $S D=0.80$ ) emotion regulation and discussed a positive and a negative memory with their child (resulting in 275 conversations). Multilevel analyses showed that children's rated engagement during the conversation was higher when parents were observed to use autonomy-supportive, elaborative, and positive evaluative reminiscing, while children's rated disaffection was predicted by low autonomy support, low elaboration, and negative evaluation. Parental positive evaluation also related positively to children's memory performance. With respect to emotion regulation, only parents' negative evaluation when talking about negative memories related to higher emotional lability.
\end{abstract}

Keywords: autonomy support, elaboration, evaluation, reminiscence, emotion regulation

Supplemental materials: http://dx.doi.org/10.1037/dev0001048.supp

Parent-child conversations about past events, also referred to as parent-child reminiscence or parent-guided reminiscence (Fivush, Haden, \& Reese, 2006), is part of everyday social interactions within virtually all families. Research suggests that parents' style of reminiscing with their child, as reflected in the degree of elaboration (i.e., expanding on the child's contributions to the conversation by using questions and statements that

This article was published Online First July 2, 2020

(D) Jolene van der Kaap-Deeder, Department of Psychology, Norwegian University of Science and Technology; Bart Soenens, Department of Developmental, Social, and Personality Psychology, Ghent University; (D) Athanasios Mouratidis, Department of Psychology, Bilkent University; (D) Sarah De Pauw, Department of Special Needs Education, Ghent University; Peter Krøjgaard, Center on Autobiographical Memory Research, Department of Psychology and the Behavioral Sciences, Aarhus University; Maarten Vansteenkiste, Department of Developmental, Social, and Personality Psychology, Ghent University.

Correspondence concerning this article should be addressed to Jolene van der Kaap-Deeder, Department of Psychology, Norwegian University of Science and Technology, Dragvoll, Edvard Bulls veg 1, 7491 Trondheim, Norway. E-mail: Jolene.van.der.Kaap-Deeder@ntnu.no add new information or focus on a new aspect), evaluation (i.e., confirming or negating the child's input), and autonomy support (i.e., following the child's rhythm of disclosure), differs considerably between parents (e.g., Cleveland \& Reese, 2005). Further, several previous studies have shown that elaboration and evaluation primarily relate to children's provision of new memory information regarding the past event and that parents' autonomy-supportive reminiscing relates more strongly to children's engagement during memory conversations (e.g., Cleveland, Reese, \& Grolnick, 2007), but no study so far has concurrently examined the unique roles of elaboration, positive evaluation, negative evaluation, and autonomy support in the prediction of children's memory-related functioning. We aimed to add to this limited literature by relying on an elaborate coding scheme to investigate the unique roles of reminiscing style (i.e., elaboration, evaluation, and autonomy support) for both mothers and fathers and for both positive and negative memories. Finally, we aimed to examine whether the benefits of parents' reminiscing style go beyond memory-related outcomes as such (i.e., memory performance, engagement) and also predict children's capacity for emotion regulation. We focused on preschoolers, as the preschool years constitute a critical period 
for the emergence of autobiographical memory and children's ability to coconstruct autobiographical narratives (Nelson \& Fivush, 2004).

\section{Parent-Child Reminiscence: Elaboration and Evaluation}

Most studies concerning parents' reminiscing style have focused on elaboration (e.g., Reese \& Fivush, 1993). Elaborative reminiscing involves expanding on the child's contributions to the conversation by using questions and statements that add new information or focus on a new aspect. Elaboration is often contrasted with repetitive reminiscing where parents repeat the exact content or the gist of their own previous questions or statements (e.g., Fivush et al., 2006). Besides elaboration and repetition, parents can also evaluate their child's input to the memory conversation. Whereas positive evaluation involves the provision of affirmative feedback, thereby confirming and praising the child's involvement, negative evaluation involves the negation of the child's utterances concerning the recalled past event (e.g., Fivush et al., 2006).

Previous research, mostly among parents of preschoolers, has documented that high levels of elaboration and positive evaluation and low levels of repetition and negative evaluation come with various developmental benefits, including better autobiographical memory development (Cleveland \& Reese, 2005; Cleveland et al., 2007; Leyva, Reese, Grolnick, \& Price, 2009), more coherent memories (even after controlling for children's language capacities; Salmon \& Reese, 2015), greater literacy and narrative skills, a more developed theory of mind, and a better understanding of the self and emotions (e.g., Fivush et al., 2006).

\section{Parent-Child Reminiscence: Autonomy Support}

According to self-determination theory (SDT; Ryan \& Deci, 2017), elaboration and positive evaluation enhance children's engagement and memory performance because they contribute to children's sense of competence. That is, an elaborative style provides the necessary structure and guidance for a child to competently reconstruct the past event, while positive evaluation would convey parents' trust in the child's capacity to talk about the memory. Although competence is an important ingredient of highquality conversations, autonomy is equally important, according to SDT (Ryan \& Deci, 2017). Children need to experience the freedom to discuss their memory in the way they want, and they need to experience parents' authentic interest in their perspective to volitionally open up toward the parent (e.g., Wuyts, Vansteenkiste, Mabbe, \& Soenens, 2017). Ideally, parents do not only help to recall past memories by elaborating on the child's input but also by following the child's rhythm of disclosure and by maximally attuning to the child's perspective (Cleveland \& Reese, 2005). In such instances, the child may function more authentically and volitionally during the conversation.

Conceptually, parental autonomy support involves acknowledging the child's perspective, needs, and emotions by showing an authentic interest, providing child-attuned choices when possible, offering meaningful rationales for introduced constraints, and stimulating initiative taking by the child. Autonomy support is often contrasted with a more controlling style of communication, where parents interfere with the child's natural rhythm of disclo- sure and tend to impose their perspective in an intrusive way (Soenens \& Vansteenkiste, 2010). Autonomy-supportive parenting contributes to various aspects of preschoolers' development, including their executive functioning and later academic achievement in primary school (e.g., Bindman, Pomerantz, \& Roisman, 2015). In contrast, controlling parenting has been found to predict more internalizing distress among preschoolers (Laurin, Joussemet, Tremblay, \& Boivin, 2015) as well as problems with regard to emotion regulation and inhibitory control at the age of 5 (Perry, Dollar, Calkins, Keane, \& Shanahan, 2018).

Despite the beneficial role of autonomy support in preschoolers' functioning, previous studies have yielded mixed results with respect to the relation between autonomy-supportive reminiscing and children's memory performance. Some studies reported a positive association (Larkina \& Bauer, 2010), others no association (Cleveland et al., 2007; Leyva et al., 2009), and others an association that was not consistent across time (Cleveland \& Morris, 2014; Cleveland \& Reese, 2005). Also, except for one study (Larkina \& Bauer, 2010), research did not consider the unique effects of autonomy support when controlling for evaluation. Clearly, there is a need for more research about the unique role of autonomy support, especially when predicting memory performance.

\section{Parents' Reminiscing Style and Children's Emotion Functioning}

Parent-child reminiscing about past emotional events represents a unique opportunity for parents and children to get in contact with and reflect upon the child's emotions as well as to explore the causes and consequences of emotions when the intensity of the emotions has subsided (e.g., Laible, Panfile Murphy, \& Augustine, 2013). This shared reflection upon the child's emotions, in turn, may aid the child in handling the emotional experiences that arise during the reminiscence and may contribute to the development of the child's emotion regulation strategies (Fivush et al., 2006; Salmon \& Reese, 2016). Emotion regulation is defined as the processes that individuals use to influence which emotions they have, when they have them, and how these emotions are experienced and expressed (Gross, 2002). Two emotion regulatory processes that are often distinguished are adaptive emotion regulation and emotional lability (e.g., Dunsmore, Booker, \& Ollendick, 2013). Adaptive emotion regulation refers to children's capacity to manage their emotions in a way that fits with the current situation, their developmental level, and social expectations (Shields \& Cicchetti, 1997). Emotional lability involves being highly sensitive and reactive to emotion-eliciting situations and experiencing difficulties in recovering from these elicited emotions (Pietromonaco \& Barrett, 2009).

To the best of our knowledge, only a few studies have shown so far that elaboration during parent-child reminiscing relates to children's emotional development including emotion understanding (Laible, 2004; Van Bergen, Salmon, Dadds, \& Allen, 2009), recognition of facial emotional expressions (Laible et al., 2013), and emotion regulation (Hernandez, Carmichael, Kiliç, \& Dunsmore, 2019). Likewise, the role of autonomy-supportive reminiscing in children's emotional functioning has not yet been examined thoroughly, though it is known that general parental autonomy support relates to children's adaptive emotion regulation (such as 
taking an active interest in one's negative emotions; Roth, Vansteenkiste, \& Ryan, 2019), and controlling parenting relates to maladaptive emotion regulation strategies such as feeling unable to regulate emotions or avoiding negative emotions all together (e.g., Brenning, Soenens, Van Petegem, \& Vansteenkiste, 2015). In the context of parent-child reminiscence, emotion coaching, which resembles autonomy-supportive reminiscing as it is characterized by parents accepting and acknowledging the child's emotions and helping the child to understand and deal adaptively with own emotions (Gottman, Katz, \& Hooven, 1996), was found to relate to children's emotion regulation (e.g., Dunsmore et al., 2013).

\section{Taking Into Account the Memory Valence and Parents' Gender}

Although the vast majority of research on parent-child reminiscing focused on positively valenced past experiences (Cleveland \& Reese, 2005), emerging research indicates that parents adopt a different reminiscence style when talking about negative past events thereby using more elaborations, causal and temporal language, more descriptions of mental states, and more sophisticated language compared to parent-child discourse about positive memories (e.g., Fivush et al., 2006; Salmon \& Reese, 2015). Further, Laible (2011) showed that mothers' elaborations during the discussion of a negative (but not positive) past event were related to children's emotion understanding.

Regarding the few studies that have directly compared mothers' and fathers' elaborative reminiscing style, some of these found mothers to be more elaborative than fathers (Zaman \& Fivush, 2013), while others did not report such differences (Reese \& Fivush, 1993). Nevertheless, as most studies failed to differentiate between elaboration and evaluation (e.g., Reese \& Fivush, 1993), differences between mothers and fathers in their evaluative reminiscing remain unknown and the same holds true for autonomysupportive reminiscing. Therefore, investigating differences between mothers and fathers in their reminiscing style with their children is important, yet hitherto relatively unexplored.

\section{The Present Study}

In the present study, we extend prior work in the extant literature on parent-child reminiscence in three significant ways. First, we sought to investigate the unique contribution of observed autonomy support, elaboration, positive and negative evaluation in parent-child reminiscence in the prediction of both withinconversation outcomes (i.e., children's engagement, disaffection, and memory performance) and a more general outcome (i.e., children's general emotion regulation skills as reported by the parents). Second, to obtain a reliable assessment of the various reminiscence dimensions, we employed a comprehensive coding scheme instead of making use of a single rating scale as was the case in some prior work (e.g., Cleveland \& Reese, 2005). Finally, by explicitly asking parents to discuss a positive and negative memory and by including both parents, this study examined the role of memory valence and parents' gender from a multilevel perspective.

We formulated three hypotheses and one exploratory research question. First, we anticipated significant within-person, betweenperson, and between-family variability in parents' reminiscing style and children's memory outcomes (Hypothesis 1). By including both parents and two types of memories, we were able to determine to what extent variation in parents' reminiscence style is due to differences between two recalled memories (i.e., most importantly due to the valence of the memory), due to differences in reminiscing style between the two parents, or due to differences among different families.

Second, in line with SDT and prior work (e.g., Cleveland et al., 2007), we predicted that observed competence support, as indexed by the presence of elaboration and positive evaluation and the absence of negative evaluation, would relate most strongly to children's memory performance, while observed autonomy support would relate most strongly to children's engagement (positively) and disaffection (negatively; Hypothesis 2). Note that previous studies often made use of composite scores, thereby combining elaboration and positive evaluation (e.g., Cleveland et al., 2007), elaboration and both positive and negative evaluation (e.g., Reese \& Fivush, 1993), or positive and negative evaluation (Sales, Fivush, \& Peterson, 2003). By breaking down these composite scores into their constituting dimensions, we sought to gain a more fined-grained understanding of their separate roles.

Third, we also investigated whether parents' reminiscing style would relate to children's broader emotional functioning. We reasoned that conversations about the past could be valuable for children's emotional functioning because the talk is temporally separated from the immediate experience, which allows the parent and child to more objectively deal with past emotions (Fivush et al., 2006). For this reason, we hypothesized that whereas autonomy support, elaboration, and positive evaluation would relate positively to adaptive emotion regulation and negatively to emotional lability, negative evaluation would show an opposite pattern of relations (Hypothesis 3). Finally, we explored whether the valence of the memory, parents' gender and child's age would moderate the relations between the study variables (Research Question 1).

\section{Method}

\section{Participants and Procedure}

In total, 87 families from the Dutch-speaking part of Belgium (Flanders) took part in this study. We were unable to calculate a priori the power needed for this study, as to the best of our knowledge this was the first study that examined these relations using a multilevel design. We therefore could not know a priori the variances (and covariances) of the intercepts, predictors, and residuals. We did, however, run some post hoc analyses to receive an indication of the power of our sample size. These analyses showed that even for paths which were close to the $.05 p$ value, we had a power of $80 \%$.

Families were participating in a larger study on parent-child reminiscing and child development. Both parents of each family $(N=174$ parents) participated. Mothers were between 25 and 44 years old $\left(M_{\text {age }}\right.$ mother $=34.62$ years, $\left.S D=3.91\right)$, while fathers were between 21 and 58 years old $\left(M_{\text {age }}\right.$ father $=37.33$ years, $S D=5.65)$. Children were aged $3(26.2 \%), 4(42.9 \%), 5(28.6 \%)$, or $6(2.4 \%)$ years old $\left(M_{\text {age }}=4.07\right.$ years, $\left.S D=0.80\right)$. Of all children, $46.0 \%$ were female. In most families, there were two (mother-report: 63.2\%; father-report: 62.4\%) or three (mother- 
report: $21.8 \%$; father-report: $25.9 \%$ ) children. The majority of parents followed postsecondary education (mother-report: $91.8 \%$; father-report: $74.4 \%)$ and were married $(74.7 \%)$ or living together without being married $(24.1 \%)$.

Families were recruited as part of an undergraduate course in developmental psychology. In exchange for course credits, students were asked to invite two families (excluding their own family) with a child aged between almost 3 and 6 years old. If a family had more than one child within this age range, students were asked to select the oldest child. Students were trained to approach potentially interested families and to collect the data in a 1-hr information session with the first author. Each family was visited twice within a 1-week interval, with one home visit focusing on the mother and the other on the father. The order of which parent participated first was counterbalanced across families and, hence, predetermined. In $42.4 \%$ of the families, it was the mother who participated during the first home visit, while $57.6 \%$ of the fathers participated first. During the home visit, parents first gave their written consent with regards to their participation and the participation of their child. Subsequently, parents filled out questionnaires concerning the child's overall emotion regulation and language capacity and students' assistance was provided if needed. Parents were informed that there were no right or wrong answers, that their answers would be treated in a confidential way, and that they could leave an item unanswered if they were uncertain.

After filling out the questionnaire, each parent was invited to talk about two memories, one positive and one negative, with their child, of which the order was counterbalanced across parents (50.0\% of the parents started with a positive memory). As these memory conversations took place at the children's home, we tried to ensure a quiet setting by, for instance, asking the other parent to take care of other children (if necessary). The selected memories needed to fit with a number of criteria to secure standardization. That is, discussed past events had to be shared (i.e., experienced both by the child and the parent), recent (i.e., occurred within the last month), unique (i.e., a one-time special rather than a routine event), and within a short time span (i.e., occurring within the span of 1 day). As for the selected negative memories, they needed to be of a mild instead of overly intense nature to avoid emotionally burdening the child. Example topics for the positive memories included going swimming or visiting an amusement park, while getting a minor injury or misbehavior by the child were examples of negative memories. Parents were instructed to talk about these events with their child in a way that was most natural and comfortable for both of them and they were allowed to talk as long as they wanted. Parent-child conversations were video recorded and transcribed verbatim for later coding. Due to technical failure, the parent not being able to recall a memory, or some memories not fulfilling the above stated criteria (e.g., not being a shared memory), $73(21.0 \%)$ of the 348 conversations were not retained. Based on $t$ tests, the excluded conversations did not differ from the retained ones in any of the main or demographic variables. The only variable that approached statistical significance concerned parents' gender, with nonretained fathers' conversations $(27.0 \%)$ tending to outnumber the respective mothers' conversations (14.9\%), $\chi^{2}(1)=3.39, p=.066$. Participation was voluntary and families did not obtain any reward. Ethical approval was obtained from the ethical committee of Ghent University (Approval no.: 2017/63; name of the project: "Parent-child talk about the past:
The antecedent role of mindful parenting and children's externalizing problems in parent-child reminiscing and the effect on children's emotion regulation").

\section{Coding}

Entire conversations were coded starting from the introduction of the topic until the ending of the conversation regarding this topic. Parents' utterances were coded for elaboration, positive evaluation, negative evaluation, and autonomy support during a first coding round. Children's utterances were coded for engagement, disaffection, and memory performance during a second, separate coding round.

Parental elaboration, positive evaluation, and negative evaluation. The coding scheme for parents' elaboration, positive evaluation, and negative evaluation (and nonrelevant $\operatorname{codes}^{1}$ ) was adapted from Reese and Fivush (1993). Specifically, each proposition, that is, each independent clause consisting of a unique (implied) verb (e.g., "We ate cake"), received a separate and single code. Thus, codes were mutually exclusive and exhaustive. Elaboration was coded (a) when the parent introduced the memory (e.g., "Do you remember when we celebrated your birthday?"), (b) moved the conversation to a new aspect of the event (e.g., after discussing which children were present at the party, the parent says "And what presents did you get?"), or (c) added information about a specific aspect (e.g., child recalls getting a toy car and the parent responds "Yes, it was a blue toy car"). Elaboration was contrasted with repetition, which involves the parent repeating the gist or exact content of his or her own previous statement or question (e.g., parent asks "Who was there?" and later the parent asks "Do you remember who was there?"). In line with previous research (e.g., Kulkofsky, Behrens, \& Battin, 2015), we created a relative score indicating elaborative reminiscing by dividing the number of elaborations by the number of repetitions +1 . By including +1 in the denominator we took into account that there were some parents who produced no repetitions. Although Reese and Fivush (1993) did not distinguish between positive and negative evaluations, we did make such a distinction in line with more recent studies (e.g., Cleveland et al., 2007). Positive evaluation was coded when the parent provided positive feedback regarding the child's memory performance by repeating the child utterance often in combination with an affirmative evaluation such as "Yes" or "That's right." Negative evaluation, in contrast, involved the parent negating the child's previous comment by repeating this comment often in combination with "No." Interrater reliabilities were calculated by means of intraclass correlation coefficients, with values below .50 considered to be poor, values between .50 and .75 considered to be moderate, and values above .75 considered as good (Portney \& Watkins, 2009, p. 82). Four coders independently coded 45 $(16.4 \%)$ of all retained conversations, resulting in adequate interrater reliabilities of .99 for elaboration, .93 for repetition, .98 for

\footnotetext{
${ }^{1}$ The following codes were also used to ease the coding process: Associations (i.e., statements/questions related to but not specifically about the particular past event), metamemory comments (i.e., statements/questions about the process of remembering), off-topic talk (i.e., statements/ questions about unrelated topics), clarification questions (due to the parent not hearing the child), fill-in-the-blanks (i.e., parent says a part of a sentence and the child is expected to fill in the rest), and nonclassifiable comments
} 
positive evaluation, and .75 for negative evaluation. The remaining conversations were divided across the four coders for further coding.

Parental autonomy support. Each entire conversation was coded in terms of how autonomy-supportive (3 items) and controlling ( 3 items) the parent was during the memory conversation. These items were based on previous coding schemes developed to assess autonomy support and control in task-specific parent-child interactions (Wuyts et al., 2017) or parent-child reminiscing (Cleveland \& Reese, 2005; Leyva et al., 2009). Autonomy support was assessed by rating the degree to which parents (a) responded to the child's input (e.g., child brings up a new topic "I really liked going down the slide yesterday" and the parent responds "Did you like it that you went so fast?"), (b) acknowledged the child's feelings (e.g., "I can see you're tired"), and (c) attentively listened to the child, by nodding their head or saying uh-huhs, as to maximally follow the child's rhythm of disclosure. Parental control was assessed by rating the degree to which parents (a) imposed their own agenda by determining the content of the conversation (e.g., child says "I don't want to talk about it" and the parent responds "Oh come on, just tell me something"), (b) imposed their own perspective, thereby neglecting or minimizing the child's experiences with respect to the past event (e.g., parent asks "Did you hurt yourself?", the child responds "No," and the parent says "You did! You were crying!"), and (c) interrupted the child without apologizing for doing so. All items were rated on a Likert scale ranging from 1 ([almost] never) to 5 (often).

An exploratory factor analysis using principal axis factoring was performed on the autonomy support items and the reverse coded items of control. One factor was extracted which explained $63.5 \%$ of the variance. Factor loadings ranged between .64 and .90. Based on these findings and the high negative correlation between the autonomy support and control subscale (i.e., $r=-.67, p<.001$ ), we created a composite score by averaging the autonomy support and reverse coded control items. The Cronbach's alpha of this scale was .88. Two coders independently coded 45 (16.4\%) of all retained conversations, resulting in a moderate interrater reliability of .66. The first coder coded all remaining conversations.

Children's engagement and disaffection. In line with a multidimensional view on engagement and disaffection (e.g., Skinner, Kindermann, \& Furrer, 2009), we assessed both behavioral and emotional components of engagement and disaffection. Behavioral engagement refers to effort exertion and persistence, on-task behavior and participation, whereas emotional engagement refers to positive and energized emotions (e.g., enthusiasm, interest and enjoyment; Skinner et al., 2009). Analogous with engagement, disaffection also contains a behavioral component, denoting the presence of passive behavior, being distracted and being uninterested, as well as an emotional component, denoting the experience of negative emotions such as anger, irritation, anxiety, and apathy (Skinner et al., 2009). Each conversation was coded along a continuum for how often the child was behaviorally engaged, emotionally engaged, behaviorally disaffected, and emotionally disaffected, where each of these four components was rated on a Likert scale ranging from 1 ([almost] never) to 5 (often). These four items were based on items used previously in the context of parent-child interaction with respect to a puzzle task (Wuyts et al., 2017). Items concerning behavioral and emotional engagement were averaged together, as were items concerning behavioral and emotional disaffection. Cronbach's alpha's were .88 and .60 for engagement and disaffection, respectively. Two coders independently coded $42(15.3 \%)$ of all retained conversations, resulting in adequate interrater reliabilities of .89 for engagement and .76 for disaffection. The first coder coded all remaining conversations.

Children's memory performance. In line with previous research (e.g., Cleveland \& Reese, 2005; Leyva et al., 2009), children's memory performance was coded by counting the number of propositions stated by the child that either provided (e.g., "And I also got an ice-cream!") or authentically requested (e.g., "Did you also have an ice-cream?") a new piece of information about the discussed past event. Two coders independently coded 45 (16.4\%) of all retained conversations, resulting in an adequate interrater reliability of .99 . The first coder coded all remaining conversations.

\section{Measures}

Children's emotion regulation and emotional lability. To assess children's general emotional functioning, each parent filled out the Emotion Regulation Checklist (Shields \& Cicchetti, 1997). This questionnaire consists of the subscales Emotion Regulation (11 items; e.g., "Can say when s/he is feeling sad, angry or mad, fearful or afraid") which focuses on the appropriate expression of emotions, adaptive emotion regulation, emotion understanding, and empathy and Emotional Lability (13 items; e.g., "Is prone to angry outbursts/tantrums easily") focusing on the lack of flexibility, anger, mood swings, and a high intensity of emotions. Items were rated on a Likert scale ranging from 0 (never) to 4 (almost always). The Emotion Regulation Checklist has been shown to have good convergent validity with similar instruments and to have a good reliability (Ramsden \& Hubbard, 2002; Shields \& Cicchetti, 1997). In this study, Cronbach's alpha's were .82 (mother report) and .75 (father report) for the subscale Emotion Regulation and .78 (mother report) and .82 (father report) for the subscale Emotional Lability. Mother and father reports were moderately correlated for both Emotion Regulation, $r=.46, p<.001$ and Emotional Lability, $r=.35, p<.01$.

Children's language capacity. Parents rated their child's language capacities with the scale Spraak-en taal Normen EersteLijns gezondheidszorg (SNEL; Luinge, 2005). The SNEL is aimed at assessing milestones in language development in Dutch-speaking children aged between 1 and 6 years old. This scale consists of 14 items (e.g., "Does your child understand sentences consisting of three words? (e.g., 'on the chair,' 'in the garden')". Items were answered by indicating "No" (coded as 0 ) or "Yes" (coded as 1). Cronbach's alpha's were .72 (mother report) and .52 (father report). Maternal and paternal reports were moderately correlated, $r=.54, p<.001$.

\section{Plan of Analyses}

As the data were hierarchically structured, with 2 memory conversations (i.e., Level 1) being nested within 174 parents (i.e., Level 2), who were nested within 87 families (i.e., Level 3), we employed multilevel analyses. These analyses were performed with the statistical software package MPlus 8 (Muthén \& Muthén, 1998-2017). Missing data (12.35\%) were missing completely at random, as the normed $\chi^{2} / d f(273.22 / 219)$ was 1.25 (i.e., smaller than the recommended cutoff of 2; Ullman, 2001). Therefore, we 
could use the full information maximum likelihood procedure to estimate missing data (Schafer \& Graham, 2002). To correct for non-normality-induced bias, we based model estimation on robust maximum likelihood (Finney \& DiStefano, 2006). Further, we evaluated the model fit via the $\chi^{2}$ test, the comparative fit index (CFI), the standardized root-mean-square residual (SRMR), and the roo-mean-square error of approximation (RMSEA). An acceptable fit was indicated by $\chi^{2} / d f$ ratio of 2 or below, CFI values of .95 or above, SRMR values of .08 or below and RMSEA values of .06 or below (Kline, 2005).

To decompose the variance in the observed reminiscence dimensions and in the memory-related outcomes (cf., $H_{1}$ ), seven random intercepts-only models were created to examine the percentage of variance situated at the within-person (Level 1), between-person (Level 2), or between-family (Level 3) level. Subsequently, we tested two path models. Specifically, we examined the role of parents' reminiscing style (i.e., autonomy support, elaboration, positive evaluation, and negative evaluation) in the prediction of children's memory outcomes (i.e., engagement, disaffection, and memory performance; Model 1; cf., $H_{2}$ ) and in the prediction of children's emotion outcomes (i.e., emotion regulation and emotional lability; Model 2; cf., $\mathrm{H}_{3}$ ).

In a set of exploratory analyses, we examined the possible moderating role of memory valence, parents' gender, and child's age (cf., Research Question 1). First, we examined the role of memory valence (i.e., positive vs. negative memory) by including the interactions between the standardized scores of each reminiscing dimension and memory valence as predictors to the model (in Model 1), or by entering each reminiscing dimension with respect to the positive and negative memory and as separate yet simultaneous predictors of children's emotion outcomes (in Model 2). With respect to the moderating role of parents' gender, we performed a multigroup comparison to examine whether the associations observed in Model 1 (including the significant interactions with respect to memory valence) and Model 2 would be similar for mothers and fathers. In doing so, we compared an unconstrained model, in which all path coefficients were allowed to vary between mothers and fathers with a constrained model, in which all path coefficients were set equal for mothers and fathers. Both models were compared using the Satorra-Bentler scaled chi-square test (Satorra \& Bentler, 2010). This test should be nonsignificant statistically in order to favor the constrained over the uncon- strained model. Finally, we examined the possible moderating role of the child's age by adding the interaction terms between the standardized scores of child age and of each indicator of parents' reminiscing style as predictors of each of the outcomes in Model 1 and Model 2.

\section{Results}

\section{Preliminary Analyses}

Descriptives and correlations. Descriptive statistics and bivariate correlations between the study variables can be found in Table 1 (within-person level) and Table 2 (between-person level). To examine the effects of the background variables on the outcome variables, we performed additional correlational analyses and $t$ tests. Results showed that parents' education level correlated significantly with children's engagement, $r=-.15, p=.02$ and disaffection, $r=.19, p<.01$. Results of independent-samples $t$ tests showed that girls were significantly less disengaged $(M=$ $1.56, S D=0.73)$ than boys $(M=1.76, S D=0.88)$ $t(271.88)=-2.12, p=.04$. Also, children were more disengaged when the mother $(M=1.81 ; S D=0.84)$ rather than the father $(M=1.57 ; S D=0.80)$ was the one who participated during the first home visit; $t(265)=2.36, p=.02$. Further, we found the number of children within the family and children's language capacities to be significantly correlated with children's emotional lability, $r=-.12, p=.03$ and emotion regulation, $r=.17, p<$ .01 , respectively. Parents' educational level related positively to children's emotion regulation, $r=.13, p=.02$. An independentsamples $t$ test showed that mothers reported a lower level of the child's emotional lability $(M=1.82, S D=0.35)$ than fathers $(M=1.96, S D=0.39$, respectively $) ; t(342)=-3.33, p<.01$. Finally, married parents reported a higher level of the child's emotion regulation $(M=3.46, S D=0.36)$ and a lower level of the child's emotional lability $(M=1.85, S D=0.36)$ compared to cohabiting (but not married) parents $(M=3.29, S D=0.38$ and $M=1.99, S D=0.40$, respectively); $t(338)=3.72$ and -2.92 , respectively, $p \mathrm{~s}<.001$. Child age, parent age, and the valence of the first memory of the conversation were unrelated to the outcome variables. Based on these findings, we controlled for child gender, parents' education, and parents' order of participation in Model 1, whereas we controlled for number of children within the family,

Table 1

Descriptives of and Correlations Between the Study Variables at the Within-Person Level

\begin{tabular}{|c|c|c|c|c|c|c|c|}
\hline Study variables & 1 & 2 & 3 & 4 & 5 & 6 & 7 \\
\hline \multicolumn{8}{|l|}{ Parents' reminiscing style } \\
\hline \multicolumn{8}{|l|}{ 1. Autonomy support } \\
\hline 2. Elaboration & .12 & & & & & & \\
\hline 3. Positive evaluation & $.25^{* * * *}$ & $.34^{* * * *}$ & & & & & \\
\hline 4. Negative evaluation & .06 & -.05 & .05 & & & & \\
\hline \multicolumn{8}{|l|}{ Children's memory outcomes } \\
\hline 5. Engagement & $.25^{* * * *}$ & $.31^{* * * *}$ & $.40^{* * * *}$ & -.10 & & & \\
\hline 6. Disaffection & $-.15^{*}$ & $-.26^{* * * *}$ & $-.15^{*}$ & $.15^{*}$ & $-.75^{* * * *}$ & & \\
\hline 7. Memory performance & $.26^{* * * *}$ & $.36^{* * * *}$ & $.79^{* * * *}$ & .04 & $.61^{* * * * *}$ & $-.32^{* * * *}$ & \\
\hline$M$ & 4.00 & 8.89 & 5.04 & 0.55 & 3.50 & 1.67 & 8.12 \\
\hline$S D$ & 0.76 & 7.15 & 4.64 & 1.45 & 1.05 & 0.82 & 6.70 \\
\hline
\end{tabular}

$p<.05 .{ }^{* * *} p<.001$. 
Table 2

Descriptives of and Correlations Between the Study Variables at the Between-Person Level

\begin{tabular}{|c|c|c|c|c|c|c|c|c|c|c|}
\hline Study variables & 1 & 2 & 3 & 4 & 5 & 6 & 7 & 8 & 9 & 10 \\
\hline \multicolumn{11}{|l|}{ Parents' reminiscing style } \\
\hline 1. Autonomy support PM & & & & & & & & & & \\
\hline 2. Autonomy support NM & $.58^{* * * * *}$ & & & & & & & & & \\
\hline 3. Elaboration PM & .04 & .09 & & & & & & & & \\
\hline 4. Elaboration NM & .12 & $.20^{* * *}$ & $.20^{*}$ & & & & & & & \\
\hline 5. Positive evaluation PM & $.31^{* * * *}$ & $.22^{\text {** }}$ & $.30^{\text {**** }}$ & .10 & & & & & & \\
\hline 6. Positive evaluation NM & .13 & .16 & .16 & $.22^{* *}$ & $.44^{* * * * *}$ & & & & & \\
\hline 7. Negative evaluation PM & $.13^{* \dagger}$ & .06 & -.07 & -.10 & .03 & .01 & & & & \\
\hline 8. Negative evaluation NM & -.16 & -.06 & -.05 & -.04 & -.05 & .07 & -.05 & & & \\
\hline \multicolumn{11}{|l|}{ Children's emotion outcomes } \\
\hline 9. Emotion regulation & .06 & $.16^{*}$ & .06 & .11 & .10 & .13 & -.12 & -.15 & & \\
\hline 10. Emotional lability & -.08 & -.07 & -.05 & -.08 & .01 & .05 & .05 & $.26^{* * * *}$ & $-.39^{* * * *}$ & \\
\hline$M$ & 4.09 & 3.91 & 10.53 & 7.09 & 6.49 & 3.45 & 0.63 & 0.47 & 3.42 & 1.89 \\
\hline$S D$ & 0.68 & 0.84 & 8.52 & 4.61 & 5.42 & 2.85 & 1.80 & 0.91 & 0.37 & 0.38 \\
\hline
\end{tabular}

Note. $\mathrm{PM}=$ positive memory conversation; $\mathrm{NM}=$ negative memory conversation.

${ }^{*} p<.05 .{ }^{* * *} p<.01 .{ }^{* * * *} p<.001 .{ }^{\dagger}$ Significant in its standardized but not unstandardized form $(B=.16, S E=.12, p=.18)$.

children's language capacities, and parents' education and marital status in Model 2. Note that we also examined the moderating role of parental gender in both models (see below).

Mean comparisons of parents' reminiscing style and children's memory outcomes depending on the type of memory conversation. To gain insight in the mean differences in parents' reminiscing style and children's memory outcomes across the four conversations (a positive and a negative with mother and a respective set with father), we performed a repeated measures analysis of variance with memory valence and parents' gender as two withinsubject factors. These analyses were performed on 42 families, as for only these families, data of the memory conversations were available for each of the four types of memories. As displayed in Table 3, memory valence had by far the largest effect on parents' reminiscing style and children's memory outcomes. Specifically, both parents were more autonomy-supportive, elaborative, and used more positive evaluations when they discussed a positive, compared to a negative, memory. The use of negative evaluations was similar across positive and negative memory conversations. With respect to children's memory outcomes, we found that children were most engaged and had the highest memory performance in the positive memory conversations, while their disaffection was similar across positive and negative memory conversations. Fi- nally, memory valence and parents' gender did not interact in the prediction of these constructs and only one main effect of parent gender was observed: children had a higher memory performance when talking with their mother instead of with their father.

\section{Primary Analyses}

$H_{1}$ : Variability in the memory conversation constructs. To decompose the variance in the observed reminiscence dimensions and in the memory-related outcomes, seven random interceptsonly models were created. Results of these analyses are summarized in Table 4. First, most of the variance in the reminiscence dimensions and memory outcomes was situated at the withinperson level or the level typified by differences between the two discussed memories such as the memory valence, with this variance varying between $47 \%$ to $96 \%$. Nonetheless, some parallels and some discrepancies with respect to the decomposition of variance at the three levels across the rated constructs should be noted. While the variance in autonomy support was divided more equally across the three levels, for elaboration, positive evaluation, and negative evaluation, the vast majority of the variance was situated at the within-person level. Similarly, whereas for children's engagement and disaffection the variance was more equally

Table 3

Mean Comparisons of Parents' Reminiscing Style and Children's Memory Outcomes Depending on the Type of Memory Conversation

\begin{tabular}{|c|c|c|c|c|c|c|c|}
\hline \multirow[b]{2}{*}{ Parent type of memory } & \multirow{2}{*}{$\begin{array}{c}\text { Mother positive, } \\
M(S D)\end{array}$} & \multirow{2}{*}{$\begin{array}{l}\text { Mother negative, } \\
\qquad M(S D)\end{array}$} & \multirow{2}{*}{$\begin{array}{l}\text { Father positive, } \\
\qquad M(S D)\end{array}$} & \multirow{2}{*}{$\begin{array}{l}\text { Father negative, } \\
\qquad M(S D)\end{array}$} & \multicolumn{3}{|c|}{$F$ value $\left(\eta^{2}\right)$} \\
\hline & & & & & Valence & Gender parent & Interaction \\
\hline \multicolumn{8}{|l|}{ Parents' reminiscing style } \\
\hline Autonomy support & $4.27(0.61)$ & $3.98(0.89)$ & $4.06(0.81)$ & $3.87(0.89)$ & $9.13^{* * *}(.18)$ & $1.94(.05)$ & $0.31(.01)$ \\
\hline Elaboration & $11.80(9.59)$ & $7.21(4.77)$ & $10.53(7.68)$ & $7.42(4.55)$ & $17.27^{* * * *}(.30)$ & $0.20(.01)$ & $0.48(.01)$ \\
\hline Positive evaluation & $7.10(5.40)$ & $3.67(2.71)$ & $5.95(5.13)$ & $2.62(2.65)$ & $34.27^{* * * *}(.46)$ & $2.69(.06)$ & $0.01(.00)$ \\
\hline Negative evaluation & $0.93(2.97)$ & $0.38(0.79)$ & $0.64(1.21)$ & $0.52(0.89)$ & $1.53(.04)$ & $0.08(.00)$ & $0.67(.02)$ \\
\hline \multicolumn{8}{|l|}{ Children's memory outcomes } \\
\hline Engagement & $3.95(0.95)$ & $3.35(1.14)$ & $3.75(1.01)$ & $3.21(0.96)$ & $24.15^{* * * *}(.37)$ & $1.42(.03)$ & $0.09(.00)$ \\
\hline Disaffection & $1.56(0.88)$ & $1.79(0.90)$ & $1.55(0.75)$ & $1.68(0.65)$ & $3.71(.08)$ & $0.33(.01)$ & $0.21(.01)$ \\
\hline Memory performance & $12.14(7.69)$ & $6.98(5.21)$ & $9.67(7.48)$ & $4.95(4.25)$ & $32.11^{* * * *}(.44)$ & $4.85^{*}(.11)$ & $0.08(.00)$ \\
\hline
\end{tabular}

${ }^{*} p<.05 . \quad{ }^{* *} p<.01 .^{* * *} p<.001$. 
Table 4

Percentage of Variance in the Memory Conversation Variables That Is Due to Within-Person, Between-Person, or Between-Family Variance

\begin{tabular}{lccc}
\hline \multicolumn{1}{c}{ Study variables } & $\begin{array}{c}\text { Within- } \\
\text { person } \\
\text { variance } \\
\text { (ICC) }\end{array}$ & $\begin{array}{c}\text { Between- } \\
\text { person } \\
\text { variance } \\
\text { (ICC) }\end{array}$ & $\begin{array}{c}\text { Between } \\
\text { family } \\
\text { variance } \\
\text { (ICC) }\end{array}$ \\
\hline Parents' reminiscing style & & & \\
Autonomy support & .47 & .24 & .29 \\
Elaboration & .89 & .09 & .02 \\
Positive evaluation & .81 & .12 & .07 \\
Negative evaluation & .96 & .02 & .02 \\
Children's memory outcomes & & & .22 \\
Engagement & .62 & .17 & .22 \\
Disaffection & .57 & .22 & .01 \\
Memory performance & .81 & .18 & \\
\hline
\end{tabular}

Note. $\quad$ ICC $=$ intraclass correlation.

distributed across the three levels, most of the variance with respect to children's memory performance was situated at the within-person level. Thus, although there was significant variability in some of the assessed constructs across the three levels, as can be expected on the basis of $H_{1}$, we found that most of the variance was situated at the within-person level. This finding indicates that parents' reminiscing style and children's engagement and memory performance substantially depend on the type of memory being discussed.

$\mathrm{H}_{2}$ : Parents' reminiscing style and children's memory outcomes. In a first three-level path model, we modeled at the within-person level paths from parents' autonomy support, elabo- ration, positive evaluation, and negative evaluation to children's engagement, disaffection, and memory performance, while controlling for memory valence (Model 1). We controlled for memory valence to better capture the unique effects of the different indicators of parents' reminiscing style regardless of the valence of the memory being discussed. Note that although this model was examined at the within-person level, we still modeled the betweenperson and between-family level as to account for the nested structure of the data (see Table S1 in the online supplemental materials for the unstandardized coefficients, standard errors, and probability values of this model). This model yielded a good fit $\left(\chi^{2} / d f=.00 ;\right.$ CFI $=.99 ;$ SRMR $=.02 ;$ RMSEA $\left.=.00\right)$. As displayed in Figure 1, both autonomy support and elaboration related positively to engagement and negatively to disaffection, while being unrelated to children's memory performance. Further, positive evaluation related positively to engagement and was strongly predictive of children's memory performance, while being unrelated to disaffection. Negative evaluation related positively to disaffection only. Thus, in line with $\mathrm{H}_{2}$, we found parents' reminiscing style to be meaningfully related to children's memory outcomes, but in contrast with this hypothesis we did not find a clear distinction between indicators of parents' reminiscing style in the prediction of memory performance on the one hand and engagement and disaffection on the other hand.

$H_{3}$ : Parents' reminiscing style and children's emotion outcomes. In a second structural model, we modeled at the between-person level paths from parents' reminiscing style (i.e., autonomy support, elaboration, positive evaluation, and negative evaluation) as observed in the positive memory conversation and as observed in the negative memory conversation to children's

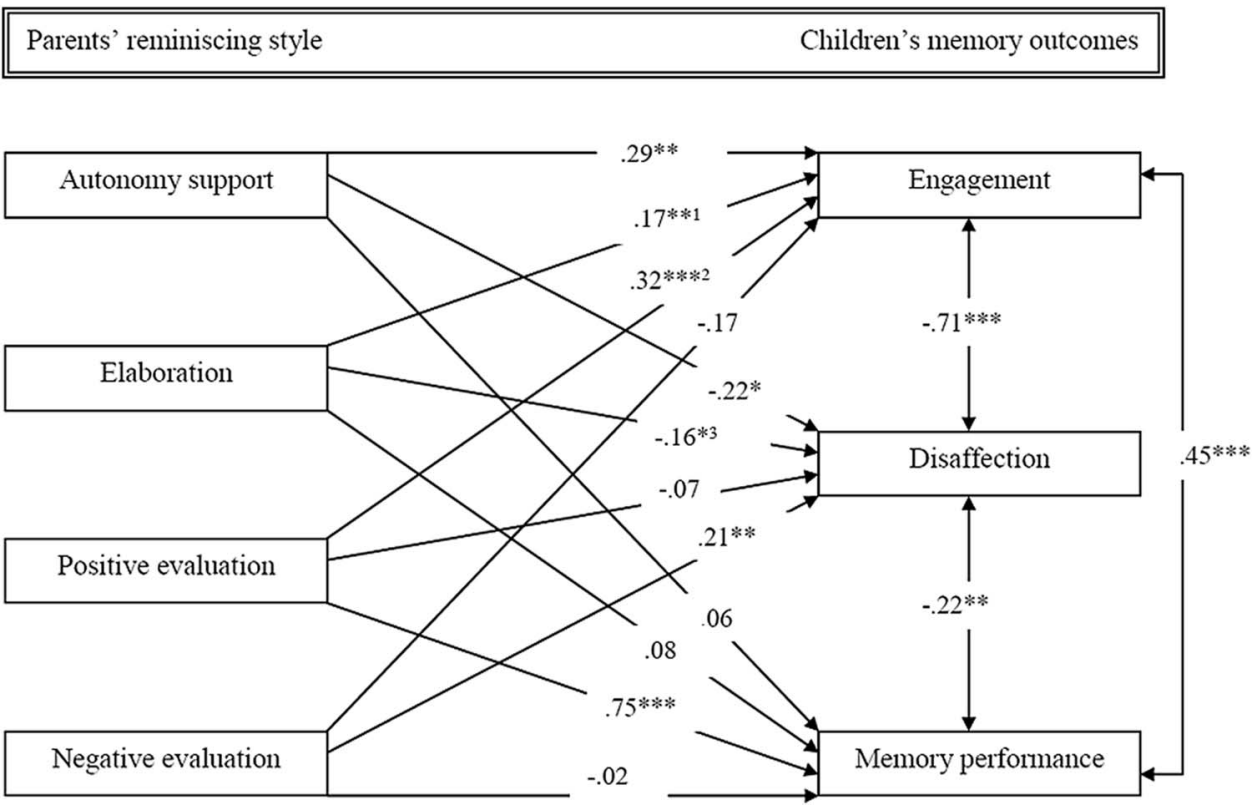

Figure 1. Structural model depicting the relation between parents' reminiscing style and children's memory outcomes. Follow-up simple slope analyses indicated that: (1) elaboration related positively to children's engagement in the negative memory conversation, but not in the positive memory conversation; (2) positive evaluation related more strongly to engagement in the negative compared to the positive memory conversation; and (3) elaboration related negatively to children's disaffection in the negative, but not in the positive memory conversation. * $p<.05$. ${ }^{* *} p<.01$. ${ }^{* * *} p<.001$. 
emotion regulation and emotional lability (Model 2). For instance, autonomy support in the positive memory and autonomy support in the negative memory conversations were added as two separate predictors. Note that, because children's emotion outcomes were situated at the between-person level, we modeled a two-level path model consisting of the between-person level variables of the original model as the Level 1 variables (to examine the relation between parents' reminiscing style and children's emotional functioning) and the between-family level variables of the original model as the Level 2 variables (to control for shared variance due to family membership; see Table S2 in the online supplemental materials for the unstandardized coefficients, standard errors, and probability values of this model). This model had a good fit $\left(\chi^{2} / d f=1.07\right.$; CFI $=.97$; SRMR $=.07$; RMSEA $\left.=.02\right)$. As displayed in Figure 2 and, in contrast with $\mathrm{H}_{3}$, we only found one significant relation between parents' reminiscing style and children's emotion outcomes. Specifically, negative evaluation in the negative memory conversation was found to relate to more emotional lability in children.

\section{Supplementary Analyses}

The moderating role of memory valence. In an explorative fashion, we examined the possible moderating role of memory valence by adding the interaction terms between memory valence and the standardized score of each indicator of parents' reminiscing style as predictors of each of the three outcomes in Model 1. Thus, 12 additional paths were added to the model (i.e., 4 interaction terms predicting each of the 3 outcomes). Of these paths, only three interactions were statistically significant. Specifically, memory valence interacted with (a) elaboration in the prediction of engagement $(\beta=.18, p<.01)$ and disaffection $(\beta=-.23, p<$ .01 ), and (b) with positive evaluation in the prediction of engagement $(\beta=.14, p<.01)$. These interactions and the corresponding follow-up simple slope analyses are displayed in Figure S1 in the online supplemental materials.

The moderating role of parent gender. To gain insight into the possible moderating role of parental gender, we examined whether Model 1 (including the three significant interactions with memory valence) and Model 2 would be similar for mothers and fathers. Results of two multigroup analyses showed that the constrained model fitted the data equally well as the unconstrained model, both for Model $1\left(\Delta \chi^{2}(21)=29.33 ; p=.11\right)$ as well as for Model $2\left(\Delta \chi^{2}(30)=30.56 ; p=.44\right)$, suggesting that the observed associations were indeed similar for mothers and fathers

The moderating role of child age. Finally, we examined whether the child's age would moderate the relations in Model 1 and Model 2. We added the interaction terms which were created by multiplying the standardized scores of child age and of each indicator of parents' reminiscing style as additional predictors of each of the three outcomes (Model 1) or two outcomes (Model 2). Of these 12 (Model 1) or 16 (Model 2) additional paths, only two interactions were statistically significant. First, in Model 1, results showed that the child's age interacted with parents' autonomy support in the prediction of disaffection $(\beta=.13, p=.03)$, while age of the child interacted with positive evaluation in the negative memory conversation in the prediction of emotion regulation ( $\beta=-.16, p=.03$ ). Both interactions showed that younger children profited more from autonomy support and positive eval-

Parents' reminiscing style

Children's emotion outcomes

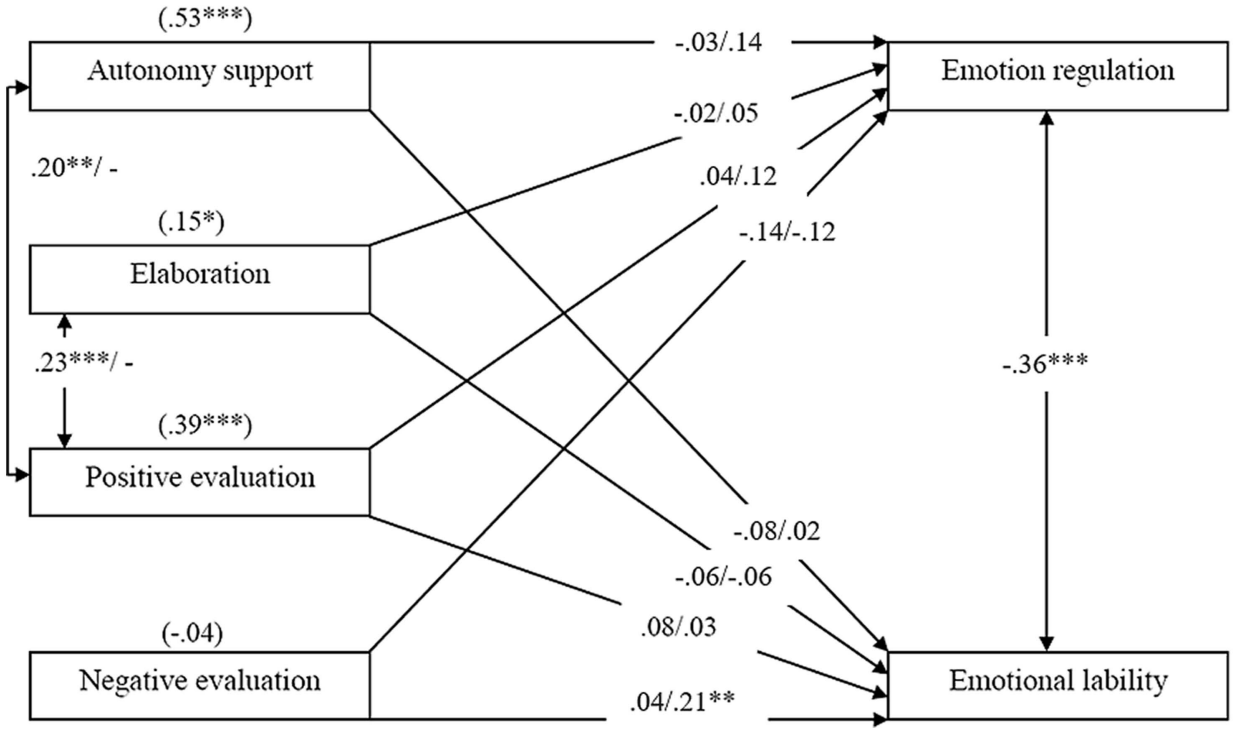

Figure 2. Structural model depicting the relation between parents' reminiscing style and children's emotion outcomes. Standardized coefficients appearing before and after the slash refer to, respectively, the positive and negative memory conversations. Values reported between parentheses refer to the correlations with respect to these variables as coded in the positive and the negative memory. ${ }^{*} p<.05$. ${ }^{* *} p<.01$. ${ }^{* * * *} p<.001$. 
uation than older children. These interactions and the corresponding follow-up simple slope analyses are displayed in Figure S2 in the online supplemental materials. To sum up, these exploratory analyses provided little evidence for the moderating role of memory valence, parent gender, and child age.

\section{Discussion}

The present study sought to investigate the unique relations of elaboration, positive evaluation, negative evaluation, and autonomy support within the context of parent-child reminiscing with children's memory-related functioning and more general emotion regulation. Besides examining these unique relations, we aimed to add to previous research by employing comprehensive coding schemes, by including mothers and fathers, and by focusing on both positive and negative memories. The design of this study allowed us to apply a multilevel approach to a total of 275 memory conversations.

\section{Variability in Parents' Reminiscing Style and Children's Memory Outcomes}

A first striking finding is that most of the variance in parents' elaboration, parents' evaluation, and children's memory performance was situated at the within-person level, indicating that these constructs are strongly affected by factors involved in the specific memories discussed (with the valence of the memory playing an essential role). Indeed, parents engaged in substantially more elaboration and more positive evaluation when discussing a positive memory compared to a negative memory. This is in contrast with previous research showing that parents elaborate more when discussing negative memories with their child (e.g., Fivush et al., 2006; Salmon \& Reese, 2015). This apparent discrepancy in results could be due to a different operationalization of elaboration. For instance, Sales et al. (2003) differentiated between open-ended and closed-ended (i.e., yes-no questions) elaboration (which was not the case in the current study) and showed that whereas openended elaboration was more frequent when discussing a negative memory, a higher proportion of closed-ended elaboration was found for positive memory conversations. Further, most of the variance in negative evaluation was also situated at the withinperson level, although there were no significant mean-level differences in negative evaluation across positive and negative memory conversations. This indicates that there are other factors at the within-person level, such as the vividness or the intensity of the memory, which might explain why the variance of negative evaluation was mostly situated at this level.

In general, these findings suggest that parental elaboration and evaluation should probably not be seen as trait-like dimensions reflecting a rather dispositional parental style. Instead, differences in parental use of elaboration and evaluation appear to be driven more strongly by situational differences in the type of memory discussed. Although previous longitudinal studies have shown parents' degree of elaboration to be quite stable across longer periods (e.g., Reese et al., 1993), other studies have shown that parents are not or only moderately consistent in their degree of elaboration, repetition, and evaluation across positive and negative memories (Fivush, Marin, McWilliams, \& Bohanek, 2009) and that parents can be trained to become more elaborative (Cleveland
\& Morris, 2014), indicating the malleability of parents' reminiscing style. More generally, our findings mesh with increasing evidence that parental behavior varies substantially on a situational basis (e.g., Repetti, Reynolds, \& Sears, 2015). Similarly, children's memory performance was mainly a function of the nature of the memory (with children performing better in positive, compared to negative, memories) and, to a much lesser degree, of interindividual differences between children. Apparently, preschool children's tendency to bring new elements to a discussion of past events is not a fixed trait differing strongly between children. The valence of the memory discussed appears to be a much stronger determinant of this tendency. This is in line with previous longitudinal research showing children's elaboration to be rather inconsistent across time (Reese et al., 1993). Nonetheless, there was a small effect of parent gender with children having a better memory performance when discussing memories with their mother instead of with their father.

With respect to parents' autonomy support and children's engagement and disaffection, results showed that the variance was divided more equally across the three levels of analysis. Thus, the degree to which parents are autonomy supportive and children are engaged or display disaffection within this context is not predominantly determined by features of the memory but also by characteristics of the parent and the family. Some parents are generally more autonomy-supportive during reminiscence (across types of memories) than other parents, although there was still an effect of memory valence with parents being more autonomy-supportive in positive compared to negative memory conversations. In some families, there is even a more autonomy-supportive climate during reminiscence (across parents) than in other families. These findings are consistent with recent diary studies showing that general autonomy-supportive parenting varies to some extent on a day-today basis yet also contains more stable components reflecting differences between parents and between families (e.g., van der Kaap-Deeder, Vansteenkiste, Soenens, \& Mabbe, 2017). The same reasoning applies to children's engagement and disaffection, where the variance was also more divided across the three levels (although children were overall more engaged in positive, compared to negative, memory conversations). In contrast to children's memory performance, there were substantial between-family differences in children's engagement and disaffection. Thus, in some families, children were overall more engaged or displayed more disaffection, regardless of the memory valence or whether they reminisce with their father or mother. These between-family differences might be reflective of the general autonomy-supportive climate within the family.

\section{Parents' Reminiscing Style and Children's Memory Outcomes}

The central aim of this study was to examine the unique relations between several dimensions of parents' reminiscing style and children's engagement and memory performance during memory conversations. Consistent with the few previous studies, we found that parental elaboration and positive evaluation related positively to children's engagement during memory conversations. Conversely, low elaboration and negative evaluation were related to children's disaffection. Parents' use of positive evaluations related positively to children's memory performance. These consistent 
associations suggest that encouraging children's competence in remembering by providing positive feedback enhances not only children's active involvement during reminiscence but also children's memory performance. Indeed, positive feedback conveys parental confidence in the child's ability to meaningfully contribute to the conversation, thereby potentially enhancing children's feelings of competence during reminiscence. With a stronger faith in their ability to contribute substantially to the conversation, children are more inclined to be fully engaged and to take the initiative to bring new elements to the conversation. This was especially the case for negative memory conversations, as our interaction analyses showed that positive evaluation related more strongly to engagement in the negative memory conversation compared to the positive memory conversation. Also, elaboration only related to children's engagement and disaffection in the negative but not positive memory conversation. These findings are in line with previous research (Laible, 2011) and are promising as keeping children engaged when jointly recalling negative experiences is more challenging for parents. Surprisingly and in contrast with previous research (Fivush et al., 2006), we found no relation between elaboration and children's memory performance. It is important to note, however, that this probability value almost reached significance (i.e., $p=.055$ ). Further, the weak effect of elaboration could also be due to the overpowering strong effect of positive evaluation on memory performance. As previous studies often combined elaboration with positive evaluation (e.g., Cleveland et al., 2007), it is interesting to see that positive evaluation may especially drive effects observed in earlier studies.

Importantly, an autonomy-supportive parental style was found to explain additional variance over and above parental elaboration and evaluation in the prediction of children's engagement. The children were more engaged and less disaffected when parents interacted with them in autonomy-supportive ways during the conversation. To date, only a few studies addressed simultaneously the roles of parental autonomy support and elaboration (e.g., Cleveland \& Reese, 2005). Our results are generally in line with these previous studies, most of which also demonstrated a unique effect of autonomy support over and above parents' elaborative reminiscing style. Almost all of these previous studies, however, used the coding scheme as developed by Cleveland and Reese (2005) which assesses the degree to which the parent follows or elaborates on the input of the child (in line with one of the items used in this study to capture autonomy support). In contrast, our measure of autonomy support involved a more encompassing and valid operationalization of autonomy support. Current findings suggest that it is important for parents to support their children's sense of autonomy, which can occur through a variety of practices. Autonomy-supportive reminiscing was not related to children's memory performance, which is in line with previous research (e.g., Cleveland et al., 2007). On the contrary, the contribution of autonomy support was not moderated by memory valence, suggesting that an autonomy-supportive reminiscence style is critical across positive and negative memories.

The current findings also showed that the relations of parents' reminiscing style were not moderated by parents' gender, indicating that parent-child reminiscing is not gendered. It is important to note, however, that some previous studies employing United States samples did show mothers to be more elaborative than fathers (Zaman \& Fivush, 2013). Perhaps this diversion reflects a cultural difference, with European fathers and mothers being more similar in their reminiscing style than American fathers and mothers.

\section{Parents' Reminiscing Style and Children's Emotion Outcomes}

Although at the correlational level, observed autonomy support and negative evaluation during the negative memory conversation related positively to parent-rated adaptive emotion regulation and emotional lability respectively, only the effect of negative evaluation remained significant in the path model. Thus, especially the communication of negative evaluations seems to relate to children being highly sensitive and reactive to emotion-eliciting situations. Parents who frequently employ negative evaluations are perhaps, in general, more critical of their child. Research has indeed shown that parental criticism, in general, undermines children's capacity for emotion regulation (Han \& Shaffer, 2014), presumably because children of highly critical parents feel helpless in dealing with negative emotions that may be more overwhelming for them.

More generally, associations between parents' reminiscing style and children's overall emotion regulation were very limited. This might be related to our finding that parents' reminiscing style in general had only a limited amount of variance at the betweenperson level, the level on which children's emotion outcomes were examined. This reduced variance at the between-person level may have reduced the predictive power of parents' reminiscing style at the between-person level. Thus, it may be more relevant to investigate outcomes of parents' reminiscing style that are situated at the within-person level, such as the child's engagement during the memory conversation. Also, because emotion regulation is a more distal outcome of parents' reminiscing style (compared to immediate memory-specific outcomes), parents' reminiscing style might be related only indirectly to emotion regulation through intervening processes. For instance, future research could examine the degree to which parents' reminiscing style contributes to children's ability to regulate emotions associated with specific memories, with this memory-specific emotion regulation perhaps serving as a stepping stone toward better emotion regulation capacities more generally.

Similar to the lack of moderating effects of parent gender, we found that children's age in general did not moderate the associations between parents' reminiscing style and the children's memory outcomes. The three significant interactions effects that were found indicated that especially younger children were more sensitive to parents' autonomy support and positive evaluation in terms of their disaffection and adaptive emotion regulation. Although these findings should be interpreted with caution as the age distribution was not equal, they do fit with the general notion that the preschool years constitute a critical period for children's ability to coconstruct autobiographical narratives (Nelson \& Fivush, 2004). When children get older they are more able to independently recall memories and are therefore perhaps also less affected by their parents' reminiscing style.

\section{Limitations and Directions for Future Research}

This study had several limitations. First, our sample was rather restricted in terms of sociodemographic characteristics, which limits the representativeness of the current sample. Moreover, 
participants were recruited via undergraduate students. Although this recruitment method has been successfully used in multiple previous studies (e.g., De Pauw, Mervielde, \& Van Leeuwen, 2009), this approach might have caused a rather biased sampling of parent-child dyads. Thus, our homogeneous sample limits the generalizability of the current findings and research within more diverse and heterogeneous samples is needed.

Second, although observational tasks were used to assess parents' reminiscing style and children's memory-related outcomes, a questionnaire was used to measure children's emotional functioning. As questionnaires have well-known disadvantages (e.g., lack of detail) and social desirability could cause parents to rate the child's emotional functioning in overly favorable ways, future research could include observational tasks of children's emotional functioning. Also, it is important to keep in mind that observations were videotaped which could have hindered parents' and children's natural interactions.

Third, an important limitation of this study is that it employed a cross-sectional correlational design, thereby being unable to shed light on the causal ordering of the study variables. The examined variables are likely to relate to one another in a reciprocal way. Indeed, Farrant and Reese (2000) showed that when children had a higher memory performance during parent-child reminiscing, mothers' elaboration increased over time. More longitudinal research is needed to test the transactional associations between parental reminiscence style and children's memory-specific outcomes.

\section{Conclusion}

Findings of this study point to the importance of both competence- and autonomy-supportive behaviors for children's engagement in parent-child reminiscence, while showing competence support to be especially relevant for children's memory performance. As we only found negative evaluation during negative memory conversations to relate to children's emotional lability, future research is needed to further explore whether and how discussing past emotions might be informative for coping with current and future emotional events. Finally, this study showed that while memory valence is a crucial element of parent-child reminiscence, parents' gender plays a much smaller role within this context.

\section{References}

Bindman, S. W., Pomerantz, E. M., \& Roisman, G. I. (2015). Do children's executive functions account for associations between early autonomysupportive parenting and achievement through high school? Journal of Educational Psychology, 107, 756-770. http://dx.doi.org/10.1037/ edu0000017

Brenning, K., Soenens, B., Van Petegem, S., \& Vansteenkiste, M. (2015). Perceived maternal autonomy support and early adolescent emotion regulation: A longitudinal study. Social Development, 24, 561-578. http://dx.doi.org/10.1111/sode. 12107

Cleveland, E. S., \& Morris, A. (2014). Autonomy support and structure enhance children's memory and motivation to reminisce: A parental training study. Journal of Cognition and Development, 15, 414-436. http://dx.doi.org/10.1080/15248372.2012.742901

Cleveland, E. S., \& Reese, E. (2005). Maternal structure and autonomy support in conversations about the past: Contributions to children's autobiographical memory. Developmental Psychology, 41, 376-388. http://dx.doi.org/10.1037/0012-1649.41.2.376

Cleveland, E. S., Reese, E., \& Grolnick, W. S. (2007). Children's engagement and competence in personal recollection: Effects of parents' reminiscing goals. Journal of Experimental Child Psychology, 96, 131-149. http://dx.doi.org/10.1016/j.jecp.2006.09.003

De Pauw, S. S. W., Mervielde, I., \& Van Leeuwen, K. G. (2009). How are traits related to problem behavior in preschoolers? Similarities and contrasts between temperament and personality. Journal of Abnormal Child Psychology, 37, 309-325. http://dx.doi.org/10.1007/s10802-0089290-0

Dunsmore, J. C., Booker, J. A., \& Ollendick, T. H. (2013). Parental emotion coaching and child emotion regulation as protective factors for children with oppositional defiant disorder. Social Development, 22, 444-466. http://dx.doi.org/10.1111/j.1467-9507.2011.00652.x

Farrant, K., \& Reese, E. (2000). Maternal style and children's participation in reminiscing: Stepping stones in children's autobiographical memory development. Journal of Cognition and Development, 1, 193-225. http:// dx.doi.org/10.1207/S15327647JCD010203

Finney, S., \& DiStefano, C. (2006). Non-normal and categorical data in structural equation modeling. In G. R. Hancock \& R. O. Mueller (Eds.), Structural equation modeling: A second course (pp. 269-314). Greenwich, London: Information Age.

Fivush, R., Haden, C. A., \& Reese, E. (2006). Elaborating on elaborations: Role of maternal reminiscing style in cognitive and socioemotional development. Child Development, 77, 1568-1588. http://dx.doi.org/10 .1111/j.1467-8624.2006.00960.x

Fivush, R., Marin, K., McWilliams, K., \& Bohanek, J. G. (2009). Family reminiscing style: Parent gender and emotional focus in relation to child well-being. Journal of Cognition and Development, 10, 210-235. http:// dx.doi.org/10.1080/15248370903155866

Gottman, J. M., Katz, L. F., \& Hooven, C. (1996). Parental meta-emotion philosophy and the emotional life of families: Theoretical models and preliminary data. Journal of Family Psychology, 10, 243-268. http://dx doi.org/10.1037/0893-3200.10.3.243

Gross, J. J. (2002). Emotion regulation: Affective, cognitive, and social consequences. Psychophysiology, 39, 281-291. http://dx.doi.org/10 1017/S0048577201393198

Han, Z. R., \& Shaffer, A. (2014). Maternal expressed emotion in relation to child behavior problems: Differential and mediating effects. Journal of Child and Family Studies, 23, 1491-1500. http://dx.doi.org/10.1007/ s10826-014-9923-6

Hernandez, E., Carmichael, K., Kiliç, S., \& Dunsmore, J. C. (2019). Linguistic indirectness in parent-preschooler reminiscing about emotionrelated events: Links with emotion regulation and psychosocial adjustment. Social Development, 28, 761-781. http://dx.doi.org/10.1111/sode .12345

Kline, R. B. (2005). Principles and practice of structural equation modeling. New York, NY: Guilford Press.

Kulkofsky, S., Behrens, K. Y., \& Battin, D. B. (2015). The bonds that remind us: Maternal reminiscing for bonding purposes in relation to children's perceived competence and social acceptance. Infant and Child Development, 24, 469-488. http://dx.doi.org/10.1002/icd.1895

Laible, D. (2004). Mother-child discourse in two contexts: Links with child temperament, attachment security, and socioemotional competence. Developmental Psychology, 40, 979-992. http://dx.doi.org/10.1037/00121649.40.6.979

Laible, D. (2011). Does it matter if preschool children and mothers discuss positive vs. negative events during reminiscing? Links with motherreported attachment, family emotional climate, and socioemotional development. Social Development, 20, 394-411. http://dx.doi.org/10 .1111/j.1467-9507.2010.00584.x

Laible, D., Panfile Murphy, T., \& Augustine, M. (2013). Constructing emotional and relational understanding: The role of mother-child remi- 
niscing about negatively valenced events. Social Development, 22, 300318. http://dx.doi.org/10.1111/sode.12022

Larkina, M., \& Bauer, P. J. (2010). The role of maternal verbal, affective, and behavioral support in preschool children's independent and collaborative autobiographical memory reports. Cognitive Development, 25, 309-324. http://dx.doi.org/10.1016/j.cogdev.2010.08.008

Laurin, J. C., Joussemet, M., Tremblay, R. E., \& Boivin, M. (2015). Early forms of controlling parenting and the development of childhood anxiety. Journal of Child and Family Studies, 24, 3279-3292. http://dx.doi .org/10.1007/s10826-015-0131-9

Leyva, D., Reese, E., Grolnick, W. S., \& Price, C. (2009). Elaboration and autonomy support in low-income mothers' reminiscing: Links to children's autobiographical narratives. Journal of Cognition and Development, 9, 363-389. http://dx.doi.org/10.1080/15248370802678158

Luinge, M. R. (2005). The language-screening instrument SNEL. Retrieved from https://research.hanze.nl/en/publications/the-language-screeninginstrument-snel

Muthén, L. K., \& Muthén, B. O. (1998-2017). Mplus user's guide (8th ed.). Los Angeles, CA: Author.

Nelson, K., \& Fivush, R. (2004). The emergence of autobiographical memory: A social cultural developmental theory. Psychological Review, 111, 486-511. http://dx.doi.org/10.1037/0033-295X.111.2.486

Perry, N. B., Dollar, J. M., Calkins, S. D., Keane, S. P., \& Shanahan, L. (2018). Childhood self-regulation as a mechanism through which early overcontrolling parenting is associated with adjustment in preadolescence. Developmental Psychology, 54, 1542-1554. http://dx.doi.org/10 .1037/dev0000536

Pietromonaco, P. R., \& Barrett, L. F. (2009). Valence focus and selfesteem lability: Reacting to hedonic cues in the social environment. Emotion, 9, 406-418. http://dx.doi.org/10.1037/a0015691

Portney, L. G., \& Watkins, M. P. (2009). Foundations of clinical research: Applications to practice (3rd ed., p. 82). London, UK: Pearson Education.

Ramsden, S. R., \& Hubbard, J. A. (2002). Family expressiveness and parental emotion coaching: Their role in children's emotion regulation and aggression. Journal of Abnormal Child Psychology, 30, 657-667. http://dx.doi.org/10.1023/A:1020819915881

Reese, E., \& Fivush, R. (1993). Parental styles of talking about the past. Developmental Psychology, 29, 596-606. http://dx.doi.org/10.1037/ 0012-1649.29.3.596

Repetti, R. L., Reynolds, B. M., \& Sears, M. S. (2015). Families under the microscope: Repeated sampling of perceptions, experiences, biology, and behavior. Journal of Marriage and Family, 77, 126-146. http://dx .doi.org/10.1111/jomf.12143

Roth, G., Vansteenkiste, M., \& Ryan, R. M. (2019). Integrative emotion regulation: Process and development from a self-determination theory perspective. Development and Psychopathology, 31, 945-956. http://dx .doi.org/10.1017/S0954579419000403

Ryan, R. M., \& Deci, E. L. (2017). Self-determination theory: Basic psychological needs in motivation, development, and wellness. New York, NY: Guilford Press.
Sales, J. M., Fivush, R., \& Peterson, C. (2003). Parental reminiscing about positive and negative events. Journal of Cognition and Development, 4, 185-209. http://dx.doi.org/10.1207/S15327647JCD0402_03

Salmon, K., \& Reese, E. (2015). Talking (or not talking) about the past: The influence of parent-child conversation about negative experiences on children's memories. Applied Cognitive Psychology, 29, 791-801. http://dx.doi.org/10.1002/acp.3186

Salmon, K., \& Reese, E. (2016). The benefits of reminiscing with young children. Current Directions in Psychological Science, 25, 233-238. http://dx.doi.org/10.1177/0963721416655100

Satorra, A., \& Bentler, P. M. (2010). Ensuring positiveness of the scaled difference chi-square test statistic. Psychometrika, 75, 243-248. http:// dx.doi.org/10.1007/s11336-009-9135-y

Schafer, J. L., \& Graham, J. W. (2002). Missing data: Our view of the state of the art. Psychological Methods, 7, 147-177. http://dx.doi.org/10 1037/1082-989X.7.2.147

Shields, A., \& Cicchetti, D. (1997). Emotion regulation among school-age children: The development and validation of a new criterion Q-sort scale. Developmental Psychology, 33, 906-916. http://dx.doi.org/10 $.1037 / 0012-1649.33 .6 .906$

Skinner, E. A., Kindermann, T. A., \& Furrer, C. J. (2009). A motivational perspective on engagement and disaffection: Conceptualization and assessment of children's behavioral and emotional participation in academic activities in the classroom. Educational and Psychological Measurement, 69, 493-525. http://dx.doi.org/10.1177/0013164408323233

Soenens, B., \& Vansteenkiste, M. (2010). A theoretical upgrade of the concept of parental psychological control: Proposing new insights on the basis of self-determination theory. Developmental Review, 30, 74-99. http://dx.doi.org/10.1016/j.dr.2009.11.001

Ullman, J. B. (2001). Structural equation modeling. In B. G. Tabachnick \& L. S. Fidell (Eds.), Using multivariate statistics (4th ed., pp. 653-771). Needham Heights, MA: Allyn \& Bacon.

Van Bergen, P. V., Salmon, K., Dadds, M. R., \& Allen, J. (2009). The effects of mother training in emotion-rich, elaborative reminiscing on children's shared recall and emotion knowledge. Journal of Cognition and Development, 10, 162-187. http://dx.doi.org/10.1080/1524 8370903155825

van der Kaap-Deeder, J., Vansteenkiste, M., Soenens, B., \& Mabbe, E. (2017). Children's daily well-being: The role of mothers', teachers', and siblings' autonomy support and psychological control. Developmental Psychology, 53, 237-251. http://dx.doi.org/10.1037/dev0000218

Wuyts, D., Vansteenkiste, M., Mabbe, E., \& Soenens, B. (2017). Effects of social pressure and child failure on parents' use of control: An experimental investigation. Contemporary Educational Psychology, 51, 378390. http://dx.doi.org/10.1016/j.cedpsych.2017.09.010

Zaman, W., \& Fivush, R. (2013). Gender differences in elaborative parentchild emotion and play narratives. Sex Roles: A Journal of Research, 68 , 591-604. http://dx.doi.org/10.1007/s11199-013-0270-7

Received July 12, 2019

Revision received March 11, 2020

Accepted May 14, 2020 